\title{
Thermomechanically coupled modelling for land-terminating glaciers: a comparison of two-dimensional, first-order and three-dimensional, full-Stokes approaches
}

\author{
Tong ZHANG, ${ }^{1}$ Lili JU, ${ }^{1}$ Wei LENG, ${ }^{2}$ Stephen PRICE, ${ }^{3}$ Max GUNZBURGER ${ }^{4}$ \\ ${ }^{1}$ Department of Mathematics and Interdisciplinary Mathematics Institute, University of South Carolina, Columbia, SC, USA \\ ${ }^{2}$ State Key Laboratory of Scientific and Engineering Computing, Chinese Academy of Sciences, Beijing, China \\ ${ }^{3}$ Fluid Dynamics and Solid Mechanics Group, Los Alamos National Laboratory, Los Alamos, NM, USA \\ ${ }^{4}$ Department of Scientific Computing, Florida State University, Tallahassee, FL, USA \\ Correspondence: Lili Ju<ju@math.sc.edu>
}

\begin{abstract}
For many regions, glacier inaccessibility results in sparse geometric datasets for use as model initial conditions (e.g. along the central flowline only). In these cases, two-dimensional (2-D) flowline models are often used to study glacier dynamics. Here we systematically investigate the applicability of a 2-D, first-order Stokes approximation flowline model (FLM), modified by shape factors, for the simulation of land-terminating glaciers by comparing it with a 3-D, 'full'-Stokes ice-flow model (FSM). Based on steady-state and transient, thermomechanically uncoupled and coupled computational experiments, we explore the sensitivities of the FLM and FSM to ice geometry, temperature and forward model integration time. We find that, compared to the FSM, the FLM generally produces slower horizontal velocities, due to simplifications inherent to the FLM and to the underestimation of the shape factor. For polythermal glaciers, those with temperate ice zones, or when basal sliding is important, we find significant differences between simulation results when using the FLM versus the FSM. Over time, initially small differences between the FLM and FSM become much larger, particularly near cold/temperate ice transition surfaces. Long time integrations further increase small initial differences between the two models. We conclude that the FLM should be applied with caution when modelling glacier changes under a warming climate or over long periods of time.
\end{abstract}

KEYWORDS: glacier flow, ice dynamics

\section{INTRODUCTION}

While mountain glaciers make up only $\sim 0.5 \%$ of the global land surface they are currently the major land-ice contributors to global sea-level rise (IPCC, 2013). Further, many alpine glaciers are located near human habitations and significantly influence local water supplies. For example, changes in the supply of meltwater produced by mountain glaciers of the Tibetan Plateau could impact as many as 1.3 billion people living downstream (Immerzeel and others, 2010). Though in situ and remote-sensing-based observations of glacier changes are being continuously carried out, they can only provide information on past or present-day changes. To predict future mountain glacier changes and their associated impacts, glacier evolution under future climates must be studied with reliable numerical ice-flow models.

Choosing an appropriate glacier model is not a simple matter: computational cost must be balanced against accuracy, and a highly accurate, expensive model may not be justified in the absence of adequate data constraints. Since the 1950s, a number of mathematical ice-flow models have been proposed, such as the shallow-ice approximation (SIA; Hutter, 1983; Morland, 1984), the shallow-shelf approximation (SSA; Morland, 1987), the so-called 'higher-order (HO)' or 'first- order (FO)' model (a first-order accurate approximation to the Stokes equations; Blatter, 1995; Pattyn, 2002, 2003), the L1L2 model (Schoof and Hindmarsh, 2010; Goldberg, 2011; Cornford and others, 2013) and so-called 'hybrid' models (a combination of the SIA and SSA; e.g.
Bueler and Brown, 2009). All are based on some approximation to the 'full', nonlinear Stokes equations, which have themselves recently been incorporated into large-scale models (Larour and others, 2012; Leng and others, 2012; Gagliardini and others, 2013), and have been used in studies of glacier and ice-sheet dynamics (e.g. Huybrechts, 1990; Saito and others, 2003; Aschwanden and Blatter, 2005; Gagliardini and others, 2007; Price and others, 2007; Seddik and others, 2012; Leng and others, 2014a).

Because of high-elevation alpine terrain and poor accessibility, geometry datasets for mountain glaciers are generally based on sparse data. This is particularly true for glaciers of the Tibetan Plateau where, for example, nearly all the in situ ice thickness data of the Himalayan East Rongbuk Glacier ( $\sim 12 \mathrm{~km}$ long) are located along its central flowline $(\mathrm{CL}), \sim 6 \mathrm{~km}$ of which is currently unsurveyed (Zhang and others, 2012, 2013). Three-dimensional (3-D) models may not be the best choice for modelling the dynamics of these glaciers, due to large uncertainties in glacier geometry, and, as a result, 2-D glacier models are widely used for studies in these areas (Oerlemans, 1986, 1997; Aschwanden and Blatter, 2005; Pattyn and others, 2005; Price and Walder, 2007; Adhikari and Huybrechts, 2009; Pimentel and others, 2010; Flowers and others, 2011; Zhang and others, 2013). Mountain glaciers are generally much narrower, and have much larger aspect ratios than ice sheets, in which case the 2-D shallow-ice and plain strain ('flowline') approximations (e.g. Cuffey and Paterson, 2010) may not apply. A standard approach is to apply a flowline model, but to adjust 
velocities along the CL using a 'shape factor' (Nye, 1965; Oerlemans, 1986; Pattyn and others, 2005; Adhikari and Marshall, 2012), which applies a correction (generally to the driving stress) to capture the influence of lateral drag from valley walls (Nye, 1965). Another approach, which we do not discuss further here, is to parameterize the lateral drag in 2-D ice-flow models using observed glacier width variations (Pimentel and others, 2010; Flowers and others, 2011; Zhang and others, 2013).

To date, few studies of mountain glaciers have included the effects of polythermal ice or have explored the importance of thermomechanical coupling. Using the EISMINT-1 geometry and environmental forcings (Huybrechts and others, 1996), Pattyn (2002) tested the transient behaviors of a 2-D FO model without coupling to the temperature field. A more rigorous investigation of higher-order ice-flow models, including applications to a realistic mountain glacier geometry, was carried out during the Ice Sheet Model Intercomparison Project for Higher-Order Models (ISMIP-HOM) (Pattyn, 2008). However, the effects of thermomechanical coupling were not considered. Recently, Adhikari and Marshall $(2011,2012)$ tried to improve the flowline model based on the SIA by parameterizing the effects of longitudinal-stress coupling and by examining shape factors for different types of glacier troughs, under both sliding and frozen bed conditions. Again, no temperature coupling was incorporated. Due to a lack of temperature observations, Adhikari and Marshall (2013) assumed a spatially uniform and constant flow law parameter, and concluded that higher-order stresses do not significantly alter the dynamics of Haig Glacier, Canada.

Because isothermal model assumptions may introduce uncertainties when applied to polythermal glaciers (e.g. those of the Tibetan Plateau), the following questions arise: (1) How do the velocity biases in 2-D flowline models influence the englacial temperature field? (2) What is the role of temperature coupling in glacier dynamics for both 2$\mathrm{D}$ diagnostic and prognostic experiments? To address these questions, we explore the impacts of (1) glacier geometry, (2) ice temperature and (3) model integration time on iceflow dynamics of land-terminating glaciers. We use a 2-D, thermomechanically coupled FO flowline model (FLM) and compare the results with a 3-D, thermomechanical, 'full'Stokes model (FSM), under identical conditions of glacier geometry, environmental forcing and boundary/initial settings. For our idealized test cases there are no observations available for use in model validation. Thus, implicit in our comparison is the assumption that solutions from the 3-D FSM are as close as possible to the 'truth'.

The paper is organized as follows: We first briefly describe the FLM and FSM used in this study. We then present a detailed description of three different experiments designed to test model sensitivities to glacier geometry, ice temperature and model integration time. We then analyze experimental results for each model, in order to comprehensively identify conditions under which FLMs provide reliable results relative to FSMs.

\section{MODEL DESCRIPTIONS}

Detailed descriptions of the FSM and the FLM used in this study are given by Leng and others $(2012,2014 a, b)$ and Greve and Blatter (2009), respectively. Verification of the FSM is discussed in detail by Leng and others (2013).

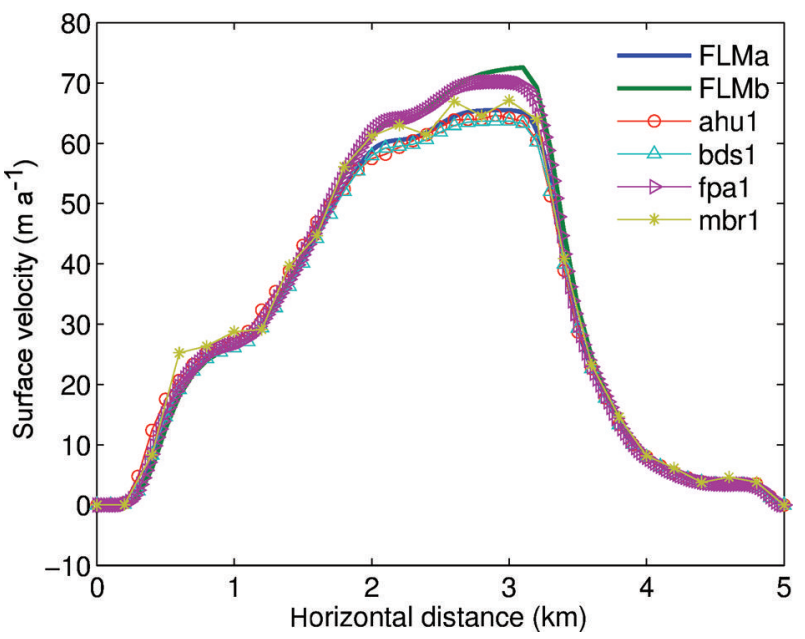

Fig. 1. Verification of the FLM. FLMa and $b$ denote surface velocities from the FLM using a horizontal grid spacing of 20 and $100 \mathrm{~m}$, respectively. Other first-order model results (ahu1, bds1, fpa1 and mbr1) shown are taken from Pattyn (2008).

The conservation of momentum for ice flow can be described by

$$
\nabla \cdot \boldsymbol{\sigma}+\rho \mathbf{g}=0,
$$

where $\boldsymbol{\sigma}$ is the full stress tensor, $\rho$ is the density of ice and $\mathbf{g}$ is the acceleration due to gravity. We note that $\boldsymbol{g}=(0,0, g)$ for the $\operatorname{FSM}$ and $(0, f g)$ for the FLM. The tensors, $\sigma$, are represented by the 3-D tensor for the FSM and the 2-D tensor for the FLM. The shape factor, $f$, is used as a correction to the body force in the FLM to parameterize the effects of drag against valley side-walls (e.g. Adhikari and Marshall, 2012). Glacier ice is generally considered an incompressible material so that

$$
\nabla \cdot \boldsymbol{u}=0,
$$

where $\boldsymbol{u}$ denotes the ice velocity vector, given by $(u, v, w)$ and $(u, w)$ for the FSM and the FLM, respectively.

The deviatoric stress is given by $\boldsymbol{\tau}=\boldsymbol{\sigma}+p \boldsymbol{I}$, where $p$ is the isotropic ice pressure $(p=-\operatorname{tr}(\sigma) / 3)$ and $\boldsymbol{I}$ is the identity matrix. The deviatoric stress is related to the strain-rate tensor, $\dot{\epsilon}$, through a constitutive law,

$$
\boldsymbol{\tau}=2 \eta \dot{\boldsymbol{\epsilon}}
$$

Glen's flow law (Cuffey and Paterson, 2010) and Eqn (3) can be combined to define the 'effective' ice viscosity, $\eta$, as

$$
\eta=\frac{1}{2} A^{-1 / n} \dot{\boldsymbol{\epsilon}}_{\mathrm{e}}^{(1-n) / n},
$$

where $n$ is the flow law exponent, $A$ is the temperaturedependent rate factor and $\dot{\boldsymbol{\epsilon}}_{\mathrm{e}}$ is the effective strain rate

$$
\dot{\epsilon}_{\mathrm{e}}=\left(\frac{1}{2} \dot{\boldsymbol{\epsilon}}: \dot{\epsilon}\right)^{1 / 2}
$$

$A$ is described by an Arrhenius-type relation

$$
A=A_{0} \exp \left(-\frac{Q}{R T}\right)
$$

with $A_{0}$ a reference flow law parameter, $Q$ the creep activation energy of ice, $R$ the universal gas constant and $T$ the ice temperature (in kelvin). Note that for the FLM, the horizontal derivatives of vertical velocity are neglected in the strain-rate computation (Greve and Blatter, 2009). Here 
Table 1. Parameters used in the numerical models

\begin{tabular}{|c|c|c|c|}
\hline Symbol & Constant & Value & Unit \\
\hline$C$ & heat capacity of ice & 2009 & $\mathrm{Jg}^{-1} \mathrm{~K}^{-1}$ \\
\hline$\gamma$ & Clausius-Clapeyron constant & $8.7 \times 10^{-4}$ & $\mathrm{~K} \mathrm{~m} \mathrm{~m}^{-1}$ \\
\hline$\gamma_{\mathrm{e}}$ & environmental lapse rate & -0.007 & $\mathrm{Km}^{-1}$ \\
\hline$\rho$ & ice density & 917 & $\mathrm{~kg} \mathrm{~m}^{-3}$ \\
\hline$\rho_{\mathrm{w}}$ & water density & 1000 & $\mathrm{~kg} \mathrm{~m}^{-3}$ \\
\hline$g$ & gravitational acceleration & 9.8 & $\mathrm{~ms}^{-2}$ \\
\hline$n$ & flow law exponent & 3 & \\
\hline \multirow[t]{3}{*}{$A_{0}$} & flow law parameter & & $\mathrm{s}^{-1} \mathrm{~Pa}^{-3}$ \\
\hline & when $T \leq 263.15 \mathrm{~K}$ & $3.985 \times 10^{-13}$ & \\
\hline & when $T>263.15 \mathrm{~K}$ & $1.916 \times 10^{3}$ & \\
\hline$G$ & geothermal heat flux & 20 & $\mathrm{~mW} \mathrm{~m}^{-2}$ \\
\hline \multirow[t]{3}{*}{$Q$} & creep activation energy & & $\mathrm{kJ} \mathrm{mol}^{-1}$ \\
\hline & when $T \leq 263.15 \mathrm{~K}$ & 60 & \\
\hline & when $T>263.15 \mathrm{~K}$ & 139 & \\
\hline k & thermal conductivity of ice & 2.1 & $\mathrm{~W} \mathrm{~m}^{-1} \mathrm{~K}^{-1}$ \\
\hline$L$ & latent heat of fusion of ice & $3.35 \times 10^{5}$ & $\mathrm{Jkg}^{-1}$ \\
\hline$R$ & universal gas constant & 8.31 & $\mathrm{~J} \mathrm{~mol}^{-1} \mathrm{~K}^{-1}$ \\
\hline$T_{0}$ & triple point of water & 273.15 & K \\
\hline
\end{tabular}

the FLM is verified by comparing model output with other FO models described by Pattyn (2008) (Fig. 1).

Conservation of energy is expressed through the advective-diffusive heat equation,

$$
\rho c\left(\frac{\partial T}{\partial t}+\boldsymbol{u} \cdot \nabla T\right)=k \nabla^{2} T+2 \eta \dot{\boldsymbol{\epsilon}}: \dot{\boldsymbol{\epsilon}},
$$

where $k$ is the conductivity and $c$ the heat capacity of ice (taken as constants here). The pressure-melting point of glacier ice, $T_{\text {pmp, }}$ is described by the Clausius-Clapeyron relation,

$$
T_{\text {pmp }}(z)=T_{0}-\gamma(s-z),
$$

where $T_{0}$ is the triple point of water, $s$ is the ice surface elevation, $\gamma$ is the Clausius-Clapeyron constant and $z$ is the vertical coordinate. In the models used in this study $T$ is set to satisfy the constraint

$$
T \leq T_{\text {pmp }}
$$

While the ice temperature is allowed to evolve in some experiments, we do not evolve the glacier geometry over time in the present work. By holding the ice geometry fixed, we can conduct grid-to-grid comparisons between the FSM and the FLM, which simplifies our understanding of the impact and importance of thermomechanical coupling (details can be found in the 'Experiment design' and 'Discussion' sections, below). Because we do not evolve the glacier geometry in time we do not present or discuss the mass-continuity equation here.

\section{Boundary conditions}

We assume a stress-free boundary condition at the upper-ice surface,

$$
\boldsymbol{\sigma} \cdot \boldsymbol{n} \simeq 0,
$$

where $\boldsymbol{n}$ is the surface normal vector.

At the lower-ice surface (i.e. the ice/bedrock interface), we set the ice velocity to zero if the ice is frozen $\left(T<T_{\mathrm{pmp}}\right)$,

$$
\boldsymbol{u}=0
$$

and, if ice temperature reaches the pressure-melting point, $T=T_{\text {pmp, }}$ we apply a linear sliding law (cf. Schoof and Hewitt, 2012):

$$
\boldsymbol{u} \cdot \boldsymbol{n}=0
$$

$$
(\sigma \boldsymbol{n}) \cdot \boldsymbol{t}+\beta \boldsymbol{u} \cdot \boldsymbol{t}=0,
$$

where $\beta$ is a positive sliding parameter and $\boldsymbol{t}$ is the lower-ice surface tangential vector. In the FLM, for numerical stability and ease of implementation we approximate this sliding law (Eqns (12) and (13)) as

$$
\sigma_{x z}+\beta u=0,
$$

similar to the approach used by Pimentel and others (2010).

For the temperature model, we set $T$ equal to the mean annual surface air temperature, $T_{\mathrm{s}}$, at the upper-ice surface. For generality, we specify these according to

$$
T=T_{\mathrm{s}}=T_{\mathrm{t}}+\gamma_{\mathrm{e}}\left(s-s_{\mathrm{t}}\right),
$$

where $\gamma_{\mathrm{e}}$ is the environmental lapse rate and $T_{\mathrm{t}}$ and $s_{\mathrm{t}}$ represent the surface air temperature and elevation at the glacier terminus, respectively. The Neumann temperature boundary condition at the ice/bedrock interface is given by

$$
\frac{\partial T}{\partial z}=-\frac{G}{k},
$$

where $G$ is the geothermal heat flux.

All model constants discussed in this section are summarized in Table 1.

\section{EXPERIMENT DESIGN}

The FSM and FLM are implemented using finite-element and finite-difference methods, respectively. To facilitate model intercomparisons, we use a layered grid for the FSM with tetrahedral-type elements: the 3-D grid is vertically extruded from a 2-D structured triangle mesh (see Leng and others, 2012, for further details). For the FLM, we use terrainfollowing coordinates: $(z \in[0,1]$; Greve and Blatter, 2009). We compare the horizontal velocity component, $u$, and ice temperature, $T$, along the $\mathrm{CL}$ of the FSM $\left(u_{\mathrm{FSM}}, T_{\mathrm{FSM}}\right)$ and the FLM $\left(u_{\mathrm{FLM}}, T_{\mathrm{FLM}}\right)$ and compute their percentage relative errors using the following error metrics (the FLM data are first linearly interpolated onto the same grid as for FSM):

$$
\begin{aligned}
& r_{u}=\frac{u_{\mathrm{FLM}}-u_{\mathrm{FSM}}}{u_{\mathrm{FSM}}} \times 100, \\
& r_{T}=\frac{T_{\mathrm{FLM}}-T_{\mathrm{FSM}}}{T_{\mathrm{FSM}}} \times 100 .
\end{aligned}
$$

The relative errors between the FLM and FSM solutions are used to identify conditions under which the FLM approximation becomes a poor approximation of the 'true' solution, which we take here as that given by the FSM.

In both models, we apply a Picard iteration for treating the nonlinearity associated with the ice viscosity. Following Gagliardini and others (2013), we set the Picard iteration convergence criterion as

$$
\frac{2\left\|\boldsymbol{u}^{I}-\boldsymbol{u}^{I-1}\right\|}{\left\|\boldsymbol{u}^{I}+\boldsymbol{u}^{I-1}\right\|}<10^{-3},
$$

where / denotes the iteration step.

A comprehensive evaluation of the FLM for use on polythermal, mountain glacier dynamics is afforded by examining the distribution of the error metrics, $r_{u}$ and $r_{T}$, as a function of ice geometry (e.g. length, slope, width, bedrock topography), temperature and model integration time. Three numerical experiments are designed as follows (Table 2). 
Table 2. Details of numerical experiments. CLG: geometry along the center flowline (CGB: slab with concave Gaussian bump; VGB: slab with convex Gaussian bump). CST: cross-sectional type (R: rectangular; U: parabolic)

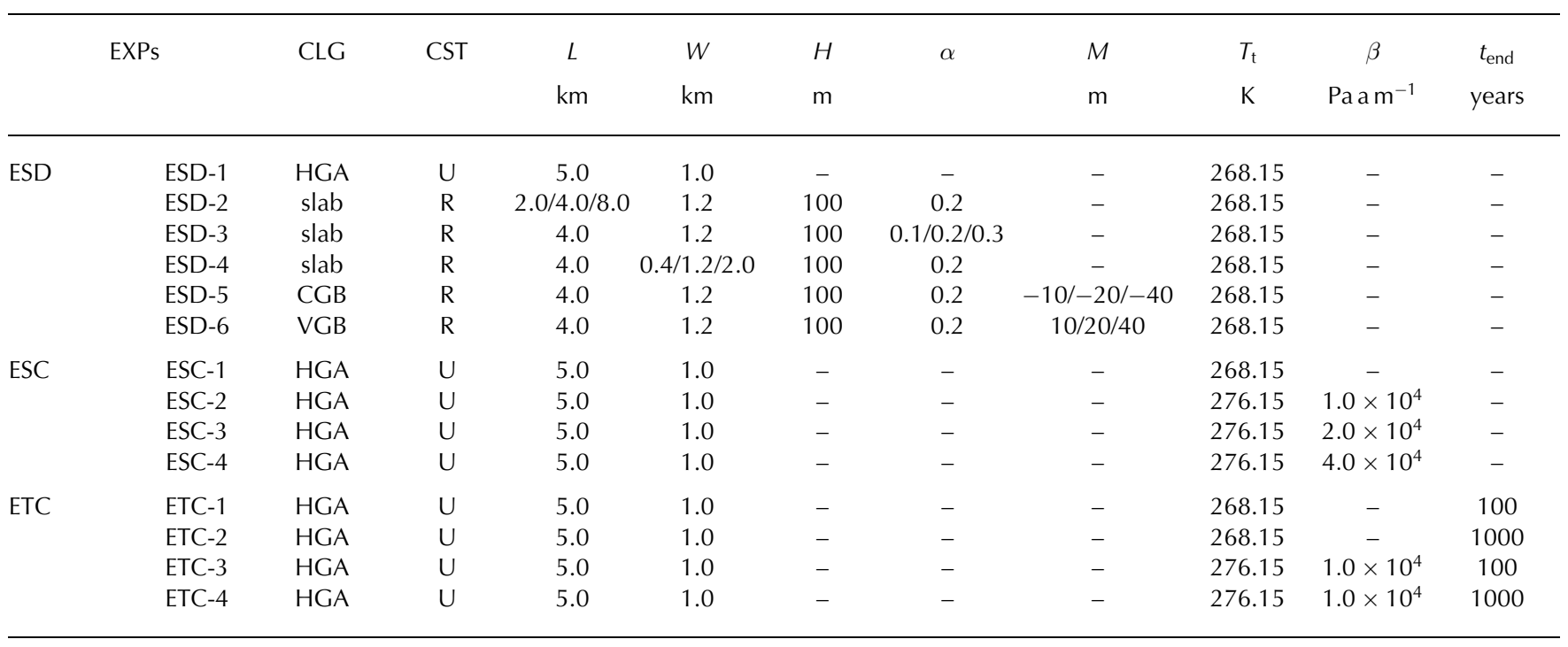

ESD: Experiments for steady-state, thermomechanically decoupled models. Similar to the EISMINT-I experiments (Huybrechts and others, 1996), we first diagnose the velocity field using a constant and uniform flow law parameter, $A=10^{-16} \mathrm{~Pa}^{-3} \mathrm{a}^{-1}$, and then use this velocity field for computing a temperature field. Thus, while we calculate both the velocity and temperature distributions, they are not coupled through the calculation of the flow law rate factor. For both the FSM and FLM models, we use the Haut Glacier $\mathrm{d}^{\prime}$ Arolla (Switzerland) CL geometry (hereafter referred to as HGA; Pattyn and others, 2008) with a uniform width of $1 \mathrm{~km}$ (ESD-1). To isolate the impact of different geometric parameters, we also model the flow within several idealized ice geometries, for example, three 'ice-slab' geometries (uniform surface slope and ice thickness) and two idealized geometries with Gaussian bumps along the bed. For the slab geometries, we vary the length, $L(2,4$ and $8 \mathrm{~km}$; ESD$2)$, surface slope, $\alpha(0.1,0.2$ and $0.3 ;$ ESD-3), and glacier width, $W(0.4,1.2$ and $2.0 \mathrm{~km}$; ESD-4). For all ice-slab model experiments, the ice thickness, $H$, is set to $100 \mathrm{~m}$ and a velocity boundary condition of $u=0$ is applied at the glacier head and terminus. To improve our understanding of the impact of extensive and compressive ice flow, we further consider slab geometries ( $4 \mathrm{~km}$ long and $1.2 \mathrm{~km}$ wide with a surface slope of 0.2 ) with perturbed concave (ESD-5; $M=-10$, $-20,-40 \mathrm{~m}$ ) or convex (ESD-6; $M=10,20,40 \mathrm{~m}$ ) Gaussian bumps along the bedrock,

$b=\left\{\begin{array}{lc}s-H, & x>0.5 L+400 \text { or } \\ s-H+M\left\{\exp \left[\frac{-(x-0.5 L)^{2}}{100 H^{2}}\right]\right\}, & 0.5 L-400<x \\ s 0.5 L+400,\end{array}\right.$

where $b$ is the bedrock elevation. Using the Gaussian bump geometries, we analyze the relative importance of pure advection and pure diffusion on the ice temperature fields between the FSM and the FLM. In
ESD-1-6, we set $T_{\mathrm{t}}=268.15 \mathrm{~K}$, which results in a frozen ice/bed interface.

ESC: Experiments for quasi-steady-state, thermomechanically coupled models. Using the fixed HGA geometry, we set $\partial T / \partial t$ to zero in Eqn (7) and recalculate $A(T)$ at every step after the velocity field is computed. Thus, for each iterative velocity solution, we calculate a corresponding steady-state temperature field. The thermomechanically coupled model runs until the $u$ and $T$ fields are converged. To study flow regimes with both frozen and thawed (i.e. sliding) beds, we set the surface temperature at the terminus, $T_{\mathrm{t}}$, to be $268.15 \mathrm{~K}$ (ESC-1) and $276.15 \mathrm{~K}$ (ESC-2) for cold and polythermal glaciers, respectively. In the case of a thawed bed, we test the model sensitivity by varying the sliding law parameter between $\beta=2 \times 10^{4} \mathrm{~Pa} \mathrm{a} \mathrm{m}^{-1}$ (ESC-3) and $\beta=4 \times 10^{4} \mathrm{~Pa} \mathrm{a} \mathrm{m}^{-1}$ (ESC-4).

ETC: Experiments for transient, thermomechanically coupled models. Like the ESC experiments, we again use the fixed HGA geometry. However, for these experiments we include the $\partial T / \partial t$ term in the temperature calculation and let it freely evolve. Two model run durations, 100 and 1000 years, are studied for both frozen and thawed (sliding) basal conditions. We use ETC-1-4 to denote experiments with the parameter pairs ( $t_{\text {end }}=100$ years, $T_{\mathrm{t}}=268.15 \mathrm{~K}$ ), $\left(t_{\text {end }}=1000\right.$ years, $\left.T_{\mathrm{t}}=268.15 \mathrm{~K}\right)$, ( $t_{\text {end }}=100$ years, $\left.T_{\mathrm{t}}=276.15 \mathrm{~K}\right)$ and $\left(t_{\text {end }}=1000\right.$ years, $\left.T_{\mathrm{t}}=276.15 \mathrm{~K}\right)$, respectively. The initial temperature fields for both the FSM and FLM are steady-state solutions taken from a purely diffusive temperature model (i.e. without heat advection) under the same boundary conditions as noted above.

Note that in the experiments above, both the FSM and the FLM have identical central flowline geometry and a horizontal grid size of $100 \mathrm{~m}$. For the FSM, we use six vertical layers, which, because the FSM uses high-order finite elements (Leng and others, 2012), provide a level of accuracy nearly identical to that when using far more (e.g. 21) vertical layers. For the FLM, there are two different 

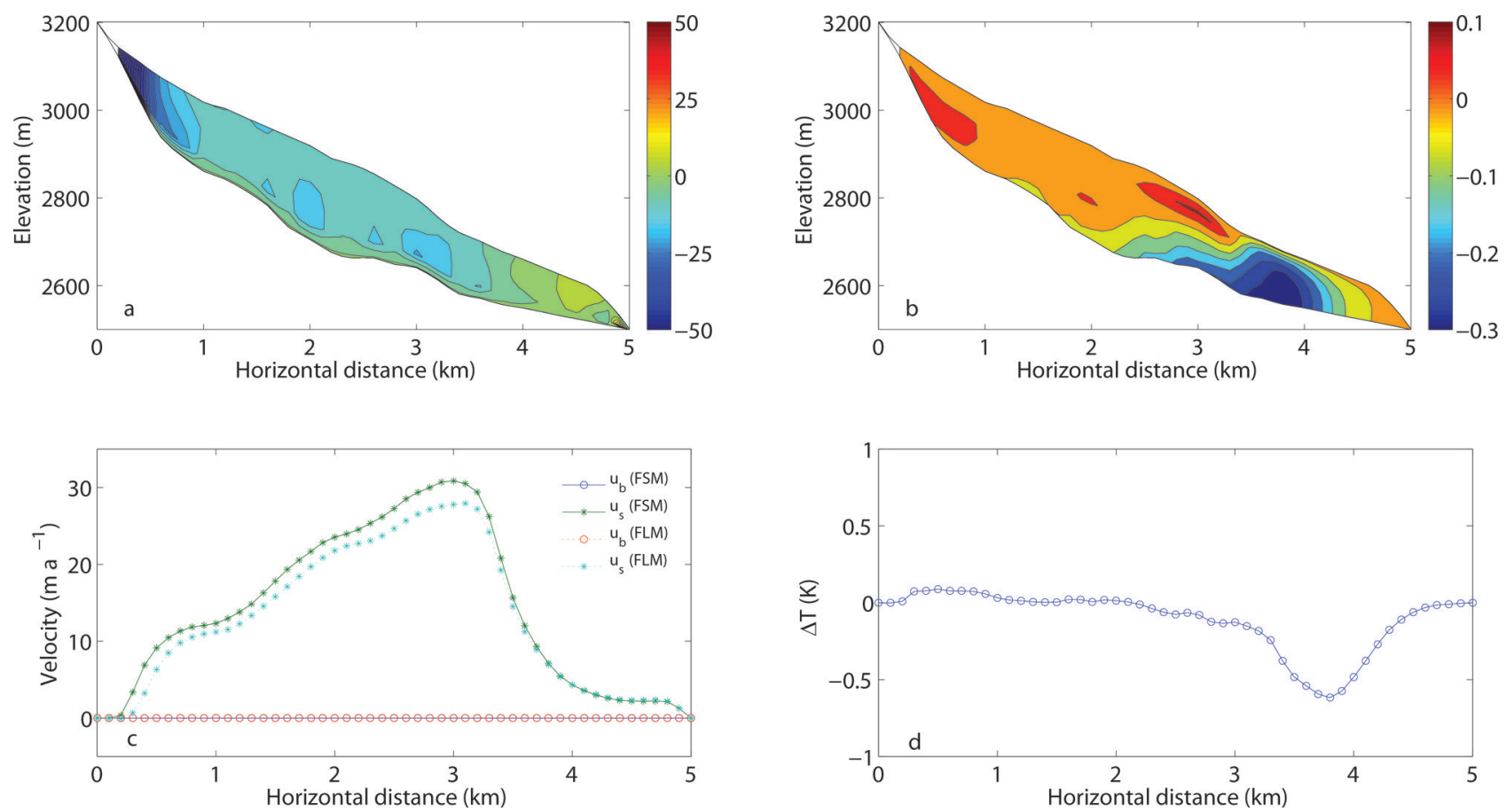

Fig. 2. ESD model results for the HGA geometry with parabolic cross sections: (a) $r_{u}$ distribution; (b) $r_{T}$ distribution; (c) surface, $u_{\mathrm{s}}$, and basal, $u_{\mathrm{b}}$, velocity of the FSM and the FLM along the CL; (d) difference of the mean column ice temperature between FSM and FLM $\left(\Delta T=\bar{T}_{\mathrm{FLM}}-\bar{T}_{\mathrm{FSM}}\right)$ along the $\mathrm{CL}$.

situations: (1) for the experiments with HGA geometry, we use 51 vertical layers; (2) for the experiments with slab and Gaussian bump geometries, we choose the vertical layer number ( 20-40) by comparing the modelled FLM and FSM velocity fields for the infinitely long and wide geometries. In other words, the number of vertical layers used for the FSM and the FLM are chosen to optimize both model performance and accuracy and to minimize differences imparted because of differing grids. The glacier cross section for HGA is assumed to be parabolic, but for ice-slab and Gaussian bump cases we set rectangular cross sections, so that we can apply periodic boundary conditions along the $x$-direction for the FLM and along both the $x$ - and $y$-directions for the FSM. The corresponding shape factor values (see Adhikari and Marshall, 2012) are linearly interpolated as a function of $x$. The geothermal heat flux is set to be uniform over the entire model domain. For the convenience of model comparisons, we simply constrain temperate ice to be not greater than $T_{\text {pmp }}$ for both the FSM and FLM, noting that this may bias model results in the cases of real glaciers (Zwinger and others, 2007).

\section{MODEL RESULTS}

\section{Results for steady-state, thermomechanically decoupled experiments (ESD)}

Shape factors are obtained from numerical experiments using infinitely long ice-slab geometries (Nye, 1965; Adhikari and Marshall, 2012). In reality, however, glaciers have finite lengths and longitudinal velocity gradients may also have a non-negligible impact on ice flow. In addition, the hydrostatic and first-order approximation that the FLM is based on will also lead to model errors. Thus, relative to simulations using the FSM, we expect biased results when using the FLM combined with a shape factor to parameterize the effects of lateral drag, $\sigma_{x y}$.
Such a bias can be observed in Figure 2. For HGA (ESD-1), the FLM produces smaller $u$ values in general and also underestimates the values of $T$ near the ice base, both of which can be largely attributed to ice geometries, as demonstrated by the ice-slab and Gaussian bump model experiments (Fig. 3). In ESD-2-6, the model sensitivities to glacier length, slope, width and Gaussian bump geometries are studied. From these experiments we find that different geometries result in different levels of velocity underestimation for the FLM, which is partly a result of approximations inherent to the FLM. In order to calculate the model error, $r_{u m}$ (as a result of the FLM approximations), we carry out experiments with no lateral drag $(f=1)$ so that $r_{u m}=r_{u}$. $r_{u m}$ is very sensitive to ice slopes and bedrock undulations (Fig. 3; ESD-3, 5 and 6).

Errors in the velocity field, $u$, result in errors in the corresponding equilibrium $T$ field. With a frozen bed, the FLM generally produces smaller $\partial u / \partial z$ values near the glacier base, and hence less shear heating. Also, the FLM retains only the $\dot{\epsilon}_{x z}$ and $\dot{\epsilon}_{x x}$ terms, while neglecting all other terms in the calculation of strain heating. Therefore, we hypothesize that the FLM results in relatively 'cooler' ice temperatures for most parts of the HGA domain.

Before exploring this further, we first confirm that the two temperature models give comparable results. As shown in Figure 4, the temperature results of the FSM (with periodic boundary conditions along the $y$-direction) compare well with those from the $\operatorname{FLM}(f=1)$ when using the same velocity field, which in both cases is taken from the FSM (blue solid curve in Fig. 4). Based on this analysis, we assume that temperature differences between the FLM and the FSM, resulting from the different model discretizations, are minor.

We next conduct a series of experiments where either the viscous dissipation or the advection components are switched 'off' in the calculation of the temperature in both 

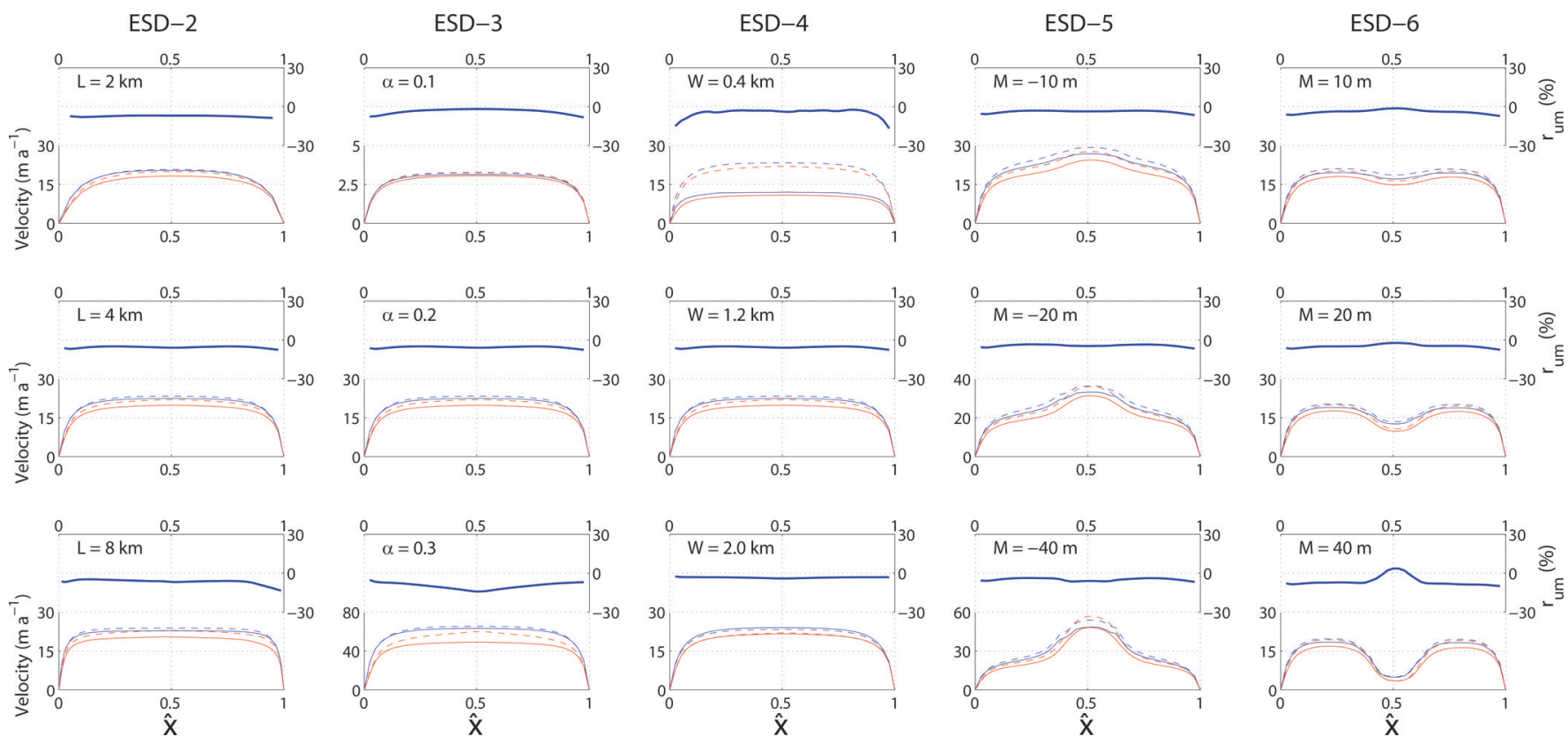

Fig. 3. Experiments ESD-2-6 with rectangular cross sections (for different glacier lengths, slopes, widths, concave Gaussian bumps and convex Gaussian bumps; Table 2). Each subplot contains two parts: (bottom) surface velocity distribution along the CL. The blue and red curves are for the FSM and FLM, respectively, while the solid and dashed curves are for experiments with lateral drag and without lateral drag (shape factor equal to 1 ), respectively; (top) the corresponding errors, $r_{u m}$, due to model simplifications, shown by the thick, solid blue curve.

the FLM and the FSM (Fig. 5). Without dissipative heating, we find that the FLM produces a slightly warmer ice (relative to the FSM), as a result of its slightly less advection of cold ice (red curves, Fig. 5). However, we can see that temperatures from the FLM are much cooler relative to the FSM in the absence of advection, when only the dissipative heating and diffusion terms act (blue curves, Fig. 5), indicating that, overall, the larger velocities of the FSM act to warm the ice rather than cool it (relative to the FLM). As a consequence, compared to the FSM, the FLM leads to generally cooler temperatures, especially near the bed, where the FLM underestimation of $\partial u / \partial z$ is large. We attribute the generally 'cool' bias of the FLM, shown by the green dashed curves in Figure 4 , to this same mechanism.

\section{Results for quasi-steady-state, thermomechanically coupled experiments (ESC)}

For the case of cold glaciers (ESC-1; Fig. 6), when coupled through the rate factor, the FLM generally produces additional biases in $u$, but there is no clear and consistent pattern whereby temperature and dynamical coupling increases or decreases the temperature biases between the FLM and the FSM: different geometries in different parts of a glacier may lead to different ice dynamics, different velocity and temperature fields, and different feedbacks between the two.

However, the results of the polythermal glacier experiment (ESC-2), in which basal sliding is allowed, are remarkably different. Both the $u$ and $T$ fields differ significantly when a temperate ice zone (TIZ) forms (Fig. 7).
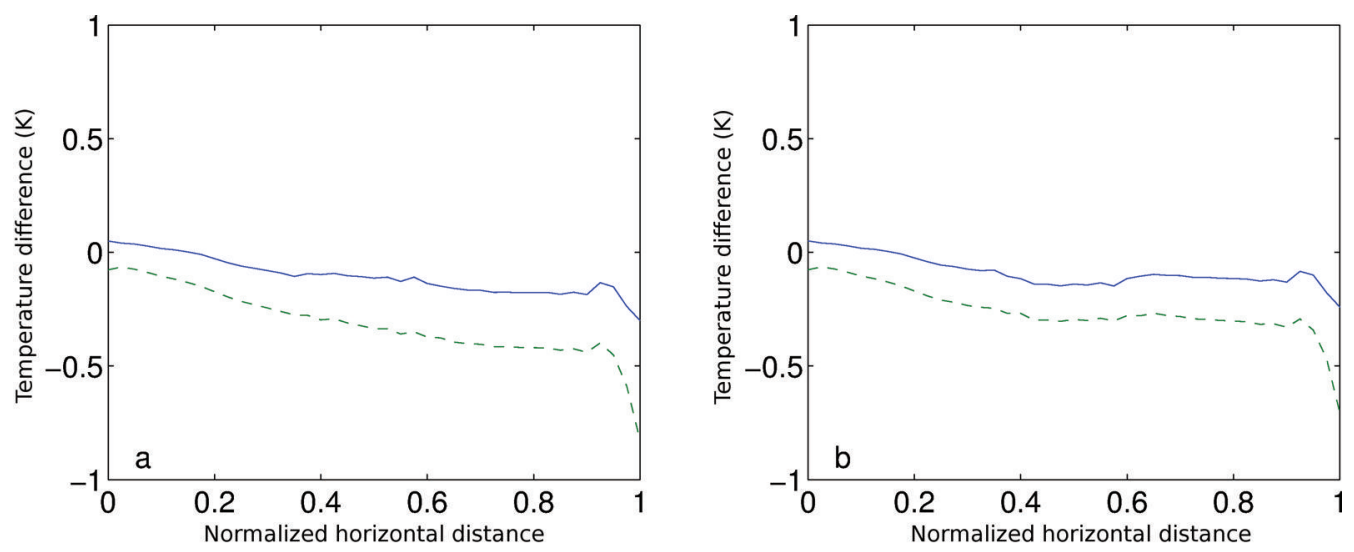

Fig. 4. Verification of the FLM temperature model. Shown are steady-state temperature differences when using (a) concave $(M=-10 \mathrm{~m})$ and (b) convex $(M=10 \mathrm{~m})$ Gaussian bump geometries with rectangular cross sections. The curves represent the difference of the mean ice column temperature along the $\mathrm{CL}$ between the FSM and the FLM $\left(\Delta T=\bar{T}_{\mathrm{FLM}}-\bar{T}_{\mathrm{FSM}}\right)$. The solid blue curve shows differences when both temperature models use the velocity field from the FSM. The dashed green curve shows differences when each model uses its own velocity field. 

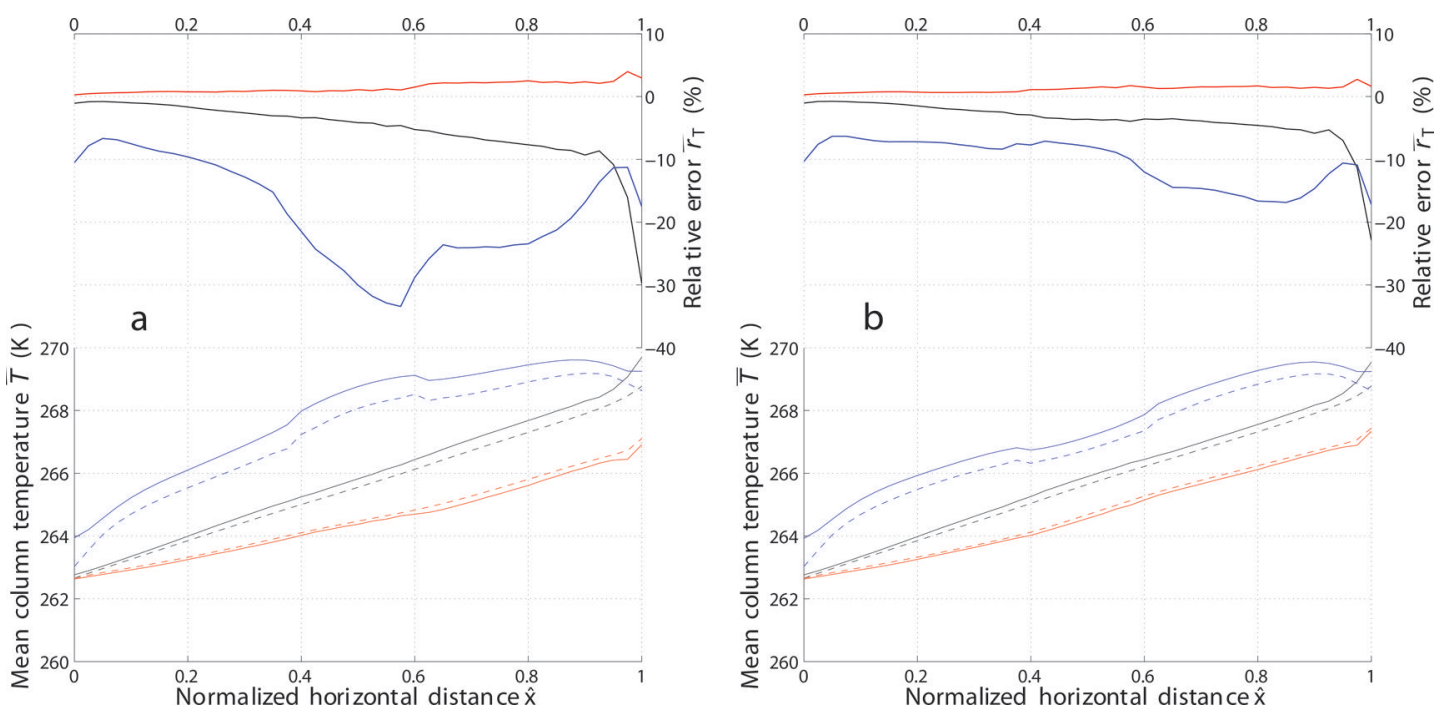

Fig. 5. The contributions of viscous heat dissipation and advection are studied using (a) concave $(M=-10 \mathrm{~m})$ and (b) convex (M=10 $\mathrm{m})$ Gaussian bump geometries without lateral drag $(f=1)$. The lower and upper figure panels show the mean column temperature profiles of FSM (solid curves) and FLM (dashed curves) and their relative errors along the central flowline, respectively. The blue, black and red curves represent temperature models without advection, complete temperature models and temperature models without viscous heat dissipation, respectively.

Compared with the FLM, the FSM produces a more extensive TIZ. Figure 7 shows that the largest differences between the modelled $u$ and $T$ occur between the cold/ temperate ice transition surfaces (CTSs). A likely cause for these differences is the presence or absence of basal sliding: since the FSM produces warmer basal ice (as discussed above) it is more likely that temperate ice appears closer to the head of the glacier relative to the FLM when the TIZ size increases. Once temperate ice appears upstream, the ice downstream of it is also more likely to be temperate, through the downstream advection of temperate basal ice, through enhanced viscous heat dissipation (afforded by more rapid deformation in soft basal ice) and through frictional heating generated by sliding (as illustrated in
Fig. 8a). For the FSM (FLM), temperate (cold) ice is transported from upstream to downstream faster as a result of sliding, with the result that the CTS positions predicted by the two models are very different in the presence of sliding (Fig. 8a). Conversely, in the absence of sliding, the CTS positions predicted by the two models are much more comparable (Fig. 8a). We can find additional evidence for this mechanism in ESC-3 and 4, for which we set the basal sliding parameter, $\beta$, to $2 \times 10^{4}$ and $4 \times{ }^{4} \mathrm{~Pa} \mathrm{a} \mathrm{m}^{-1}$ (Fig. $8 \mathrm{~b}$ ), respectively. This change leads to changes in the extents of the TIZs for the FSM and the FLM, which become more similar (their sizes are still greatly different), relative to ESC-2 $\left(\beta=1 \times 10^{4} \mathrm{~Pa} \mathrm{a} \mathrm{m}^{-1}\right)$, when $\beta$ increases (sliding velocity decreases) (Fig. 8b).
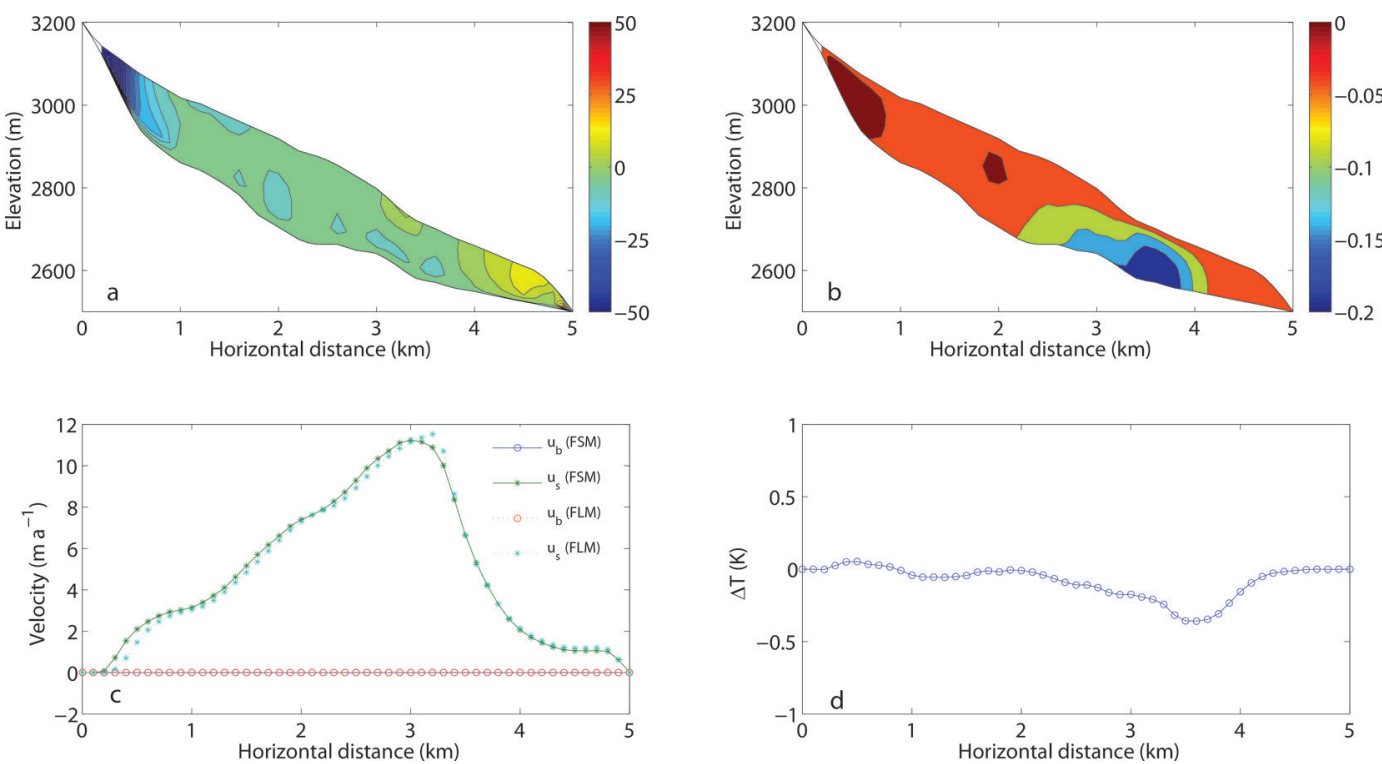

Fig. 6. ESC-1 model results for the HGA geometry with parabolic cross sections: (a) $r_{u}$ distribution; (b) $r_{T}$ distribution; (c) surface, $u_{\mathrm{s}}$, and basal, $u_{\mathrm{b}}$, velocity of FSM and FLM along the CL; (d) difference of the mean column ice temperature between FSM and FLM $\left(\Delta T=\bar{T}_{\mathrm{FLM}}-\bar{T}_{\mathrm{FSM}}\right)$ along the $\mathrm{CL}$. 

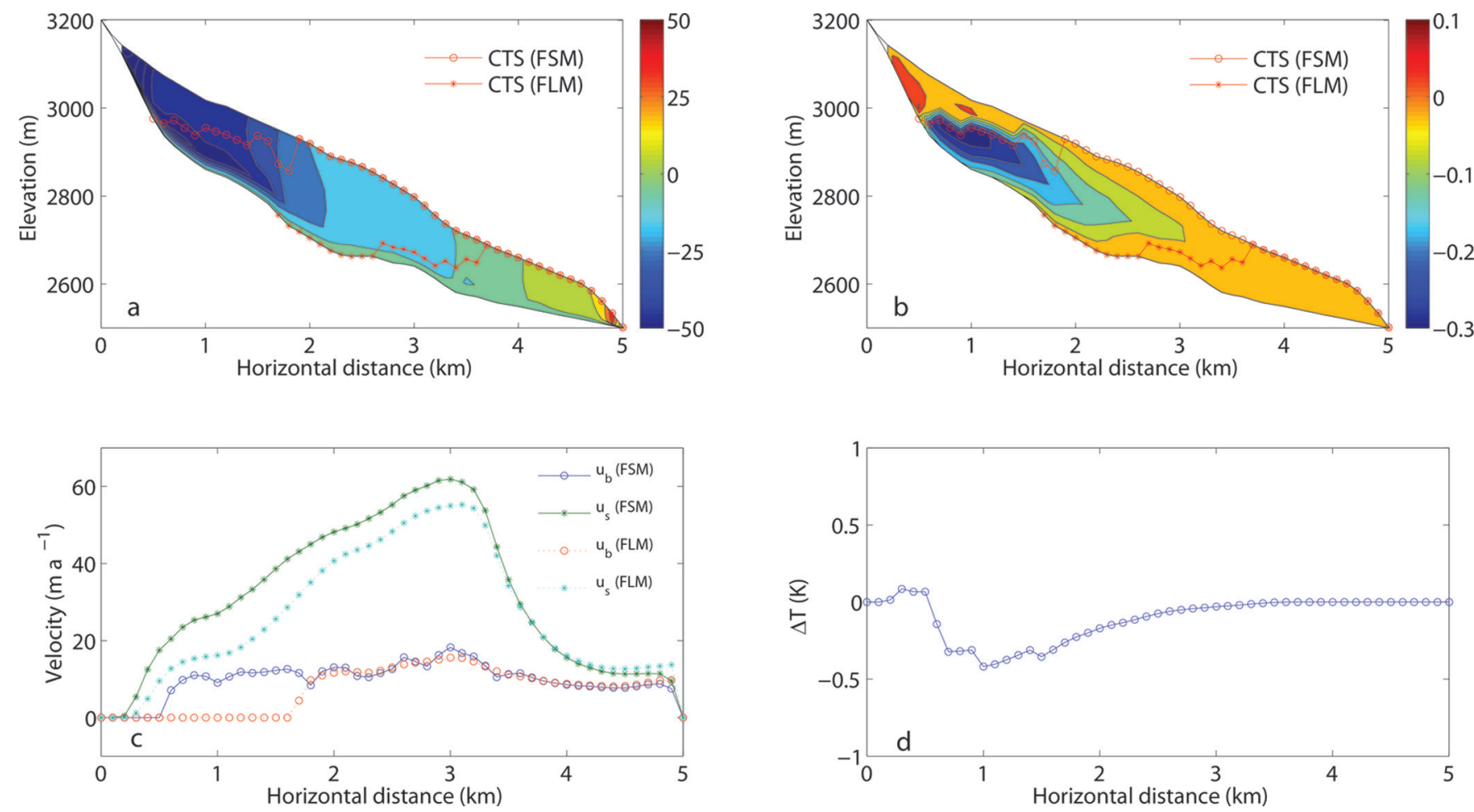

Fig. 7. ESC-2 model results for the HGA geometry with parabolic cross sections: (a) $r_{u}$ distribution (absolute values $>50 \%$ are not shown); (b) $r_{T}$ distribution; (c) surface, $u_{\mathrm{s}}$, and basal, $u_{\mathrm{b}}$, velocity of FSM and FLM along the CL; (d) difference of the mean column ice temperature between FSM and FLM $\left(\Delta T=\bar{T}_{\mathrm{FLM}}-\bar{T}_{\mathrm{FSM}}\right)$ along the CL. CTS represents the cold/temperate ice transition surface.

\section{Results of transient, thermomechanically coupled model experiments (ETC)}

To study the impact of model integration time on the differences between the FLM and the FSM, we integrate the thermomechanically coupled models forward in time while holding the domain geometry fixed (as discussed above). For the case of both frozen (no slip) and thawed (sliding) beds, we examine model differences at time steps associated with 100 and 1000 years of forward integration (Figs 9 and 10, respectively). At the beginning of the transient modelling, the temperature fields of both the FSM and FLM are initialized with pure heat diffusion $(\mathbf{u}=0)$ under the same boundary (geothermal heat flux and surface air temperature) settings.

As might be expected, we find that the discrepancies between the FLM and FSM $u$ and $T$ fields become larger over time, relative to results of the ESC experiments. For example, the $\left|r_{u}\right|$ of ETC-2 is greater than that of ETC-1 in most parts of HGA (Fig. 9). This indicates that biases between the FLM and the FSM, in both the $u$ and $T$ fields, grow over time, presumably through the feedback between $u$ and $T$ in Eqn (7). This feedback becomes even more important when the glacier is sliding, whereby the FLM versus FSM discrepancies between the $u$ and $T$ fields at integration times of 100 versus 1000 years become even larger (Fig. 10). A small initial difference in the FLM and FSM $T$ fields is magnified through the thermomechanical feedbacks discussed above, such that the final extent of the TIZs in the two models is markedly different.
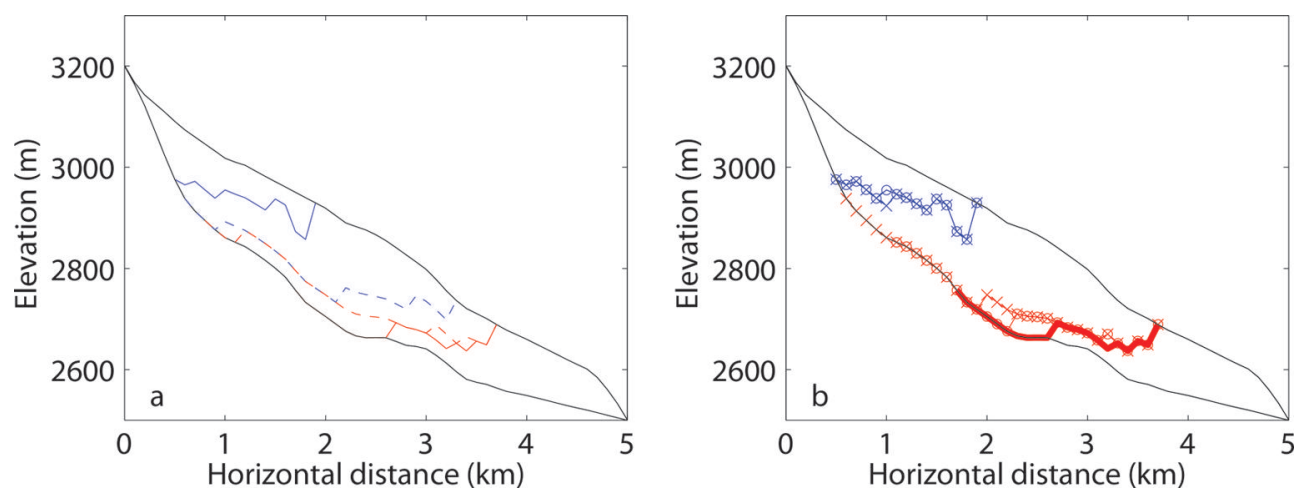

Fig. 8. Comparison of the cold/temperate ice transition surface (CTS) positions of FSM (blue curves) and FLM (red curves). (a) The solid and dashed curves represent the cases in which basal sliding is allowed and prohibited, respectively. (b) The thick solid curves, the curve with circles and the curve with crosses are for the sliding parameter $\beta=1 \times 10^{4}, 2 \times 10^{4}$ and $4 \times 10^{4} \mathrm{~Pa} \mathrm{a} \mathrm{m}^{-1}$, respectively (for the FSM, those three curves nearly overlap). The cross-sectional type is parabolic. 

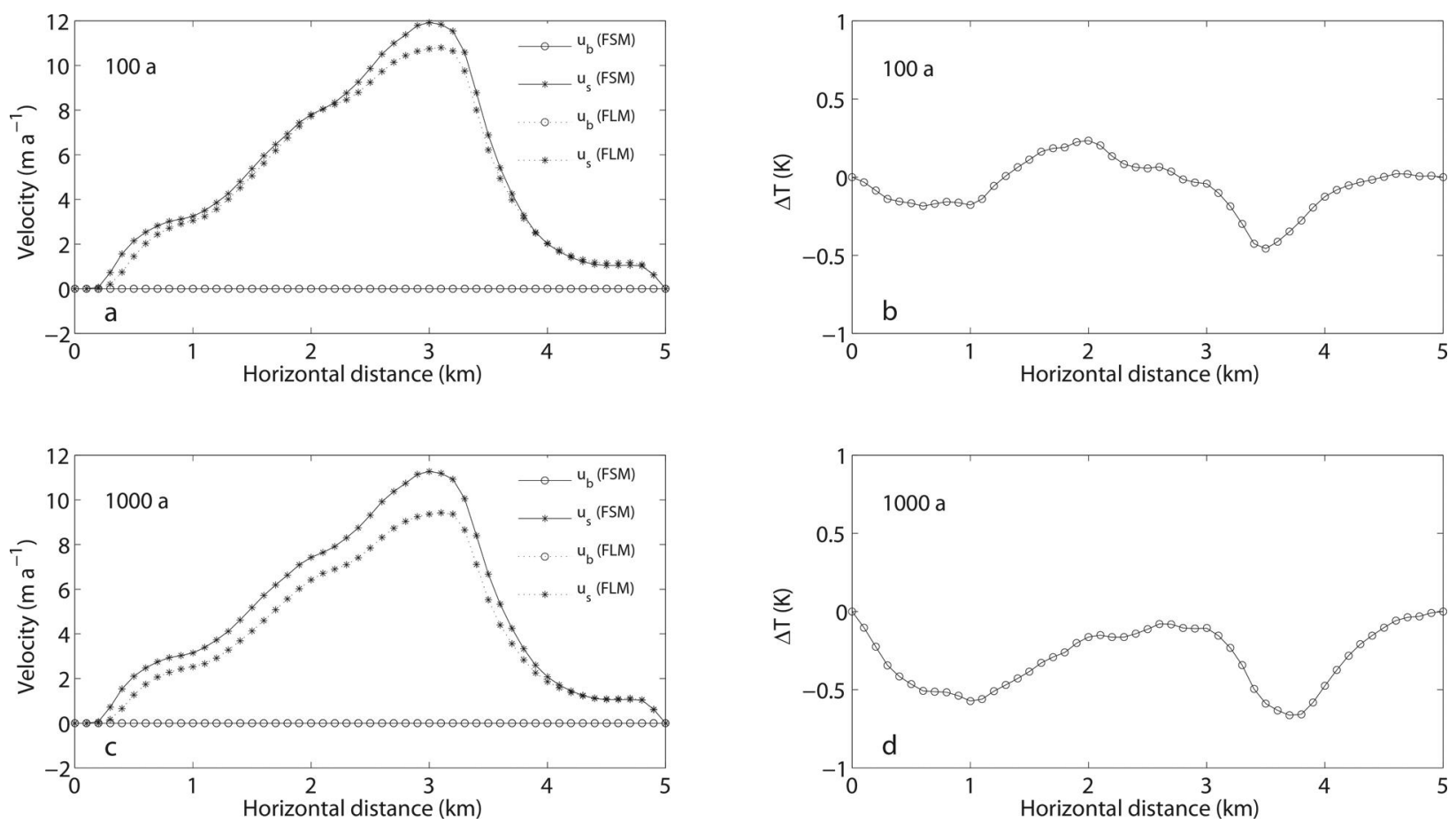

Fig. 9. ETC-1 (100 years of integration) and ETC-2 (1000 years of integration) model results for the HGA geometry with parabolic cross sections. ( $\mathrm{a}, \mathrm{c})$ surface, $u_{\mathrm{s}}$, and basal, $u_{\mathrm{b}}$, velocity of FSM and FLM along the CL. (b, d) Difference of the mean column ice temperature between FSM and FLM $\left(\Delta T=\bar{T}_{\mathrm{FLM}}-\bar{T}_{\mathrm{FSM}}\right)$ along the $\mathrm{CL}$.

\section{DISCUSSION}

In addition to the experiments discussed in detail above, we conducted model experiments using different cross-sectional shapes (rectangular rather than parabolic), using other longitudinal ice geometries (the simple analytic glacier profile presented by Le Meur and others, 2004, and Adhikari and Marshall, 2012, as opposed to the HGA geometry), and using different grid resolutions. The conclusions from these additional experiments are qualitatively similar to those described above. Real glaciers, however, have sufficiently complex and spatially varying geometries that render it impossible to conduct an exhaustive and conclusive series
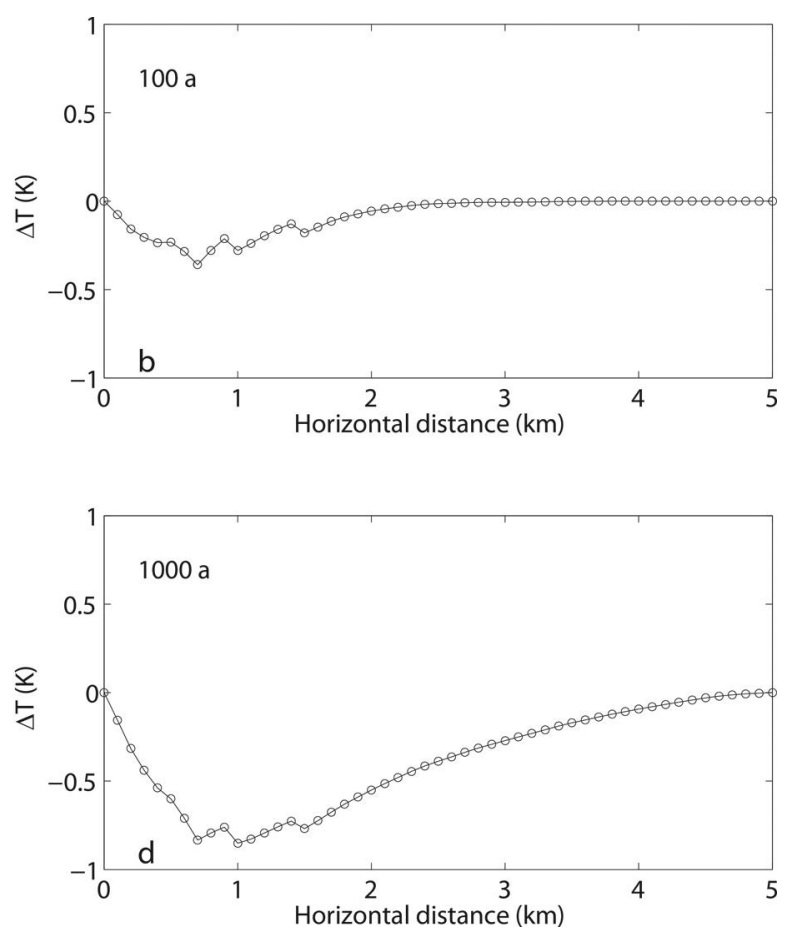

Fig. 10. ETC-3 (100 years of integration) and ETC-4 (1000 years of integration) model results for the HGA geometry with parabolic cross sections. $(\mathrm{a}, \mathrm{c})$ surface, $u_{\mathrm{s}}$, and basal, $u_{\mathrm{b}}$, velocity of FSM and FLM along the CL. (b, d) Difference of the mean column ice temperature between FSM and FLM $\left(\Delta T=\bar{T}_{\mathrm{FLM}}-\bar{T}_{\mathrm{FSM}}\right)$ along the CL. 
of experiments for more-realistic glaciers. For example, the index of the power law function that describes crosssectional shapes (2 for parabolic cross sections) will vary spatially over a wide range for real glaciers. Further, glacier cross sections are often highly unsymmetric (e.g. Zhang and others, 2012) and glacier widths are not uniform along flow (as assumed in this study). Therefore, we expect that additional errors and biases of the sort demonstrated here can be expected when applying a FLM to approximate the evolution of realistic, 3-D glaciers.

Adhikari and Marshall (2012) argued that two types of correction factors induced by glacier geometry, $f_{\mathrm{n}}$, and sliding conditions, $f_{\mathrm{s}}$, should be accounted for $\left(f=f_{\mathrm{n}} \times f_{\mathrm{s}}\right)$. In this study, we included only $f_{\mathrm{n}}\left(f=f_{\mathrm{n}}\right)$, as it would not be practical to implement $f_{\mathrm{s}}$ during the model numerical iterations and to distinguish between 'abrupt' and 'smooth' basal sliding transition regions. While we expect that the additional factor $f_{\mathrm{s}}(<1)$ could further reduce the values of $u$ in the FLM relative to the FSM (thus resulting in even larger discrepancies between the FSM and FLM results) and that different basal sliding 'laws' (e.g. Weertman-type (Cuffey and Paterson, 2010) or Coulomb- friction type (Gagliardini and others, 2007)) may introduce additional differences, our conclusion that basal sliding will enhance biases between the FLM and FSM should be robust.

While we have studied model sensitivities with respect to integration time in this paper, we have not carried out any prognostic simulations whereby the glacier geometry is allowed to change over time. Here this is because a comparison of ice-volume changes between the FSM and the FLM is far from straightforward. The $u$ profiles along glacier cross sections are not well understood (e.g. Nye, 1965), but for modelling volume evolution using a FLM a reliable parameterization of the mean, across-flow ice flux is required at each point along flow. In general, it is not clear how best to conduct a fair and meaningful comparison of glacier geometry changes as calculated by the FLM with those calculated by the FSM.

\section{CONCLUSIONS}

By comparing output from a 3-D, thermomechanical, fullStokes model (FSM) and a 2-D, thermomechanical, firstorder flowline model (FLM) we investigated model sensitivities to three different factors: glacier geometry (e.g. length, slope, width and bed undulation), ice temperature and model integration time. We find that, in common situations, the FLM will be heavily biased and should therefore be used and interpreted with caution. These situations include the simulation of (1) glaciers that are steep and with heavily undulated bed topography, (2) polythermal glaciers for which there is a temperate basal ice zone and for which basal sliding occurs and (3) glacier evolution over long time periods ( $\sim 10^{3}$ years). Put differently, the FLM is more likely to give accurate results (relative to a FSM) for flat, cold or temperate glaciers with relatively short equilibrium timescales (i.e. less than several hundred years).

Among the factors tested here, we argue that the glacier geometry (accounted for in part by the shape factor for the FLM) is likely to lead to the biggest differences in simulation outputs for the FLM versus the FSM. While the presence or absence of basal sliding leads to the largest overall model differences, this is largely a result of differences in the modelled temperature fields. These originally arise from small differences in the modelled ice velocity fields, which grow over time through positive, thermomechanical feedbacks. In turn, these initially small differences in the velocity field arise because of approximations inherent to the FLM and the way that geometry is parameterized in the FLM (i.e. using a shape factor to parameterize the effects of lateral drag).

\section{ACKNOWLEDGEMENTS}

This work is partially supported by the US Department of Energy, Office of Science, Advanced Scientific Computing Research and Biological and Environmental Research programs through the Scientific Discovery through Advanced Computing (SciDAC) project PISCEES, and by the US National Science Foundation under grant No. DMS1215659, the National 863 Project of China under grant No. 2012AA01A309 and the National Center for Mathematics and Interdisciplinary Sciences of the Chinese Academy of Sciences. We owe thanks two anonymous reviewers for their reviews of an earlier version of this paper. Weili Wang was our scientific editor.

\section{REFERENCES}

Adhikari S and Huybrechts P (2009) Numerical modelling of historical front variations and the 21st-century evolution of glacier AX010, Nepal Himalaya. Ann. Glaciol., 50(52), 27-34 (doi: 10.3189/172756409789624346)

Adhikari S and Marshall SJ (2011) Improvements to sheardeformational models of glacier dynamics through a longitudinal stress factor. J. Glaciol., 57(206), 1003-1016 (doi: 10.3189/002214311798843449)

Adhikari S and Marshall SJ (2012) Parameterization of lateral drag in flowline models of glacier dynamics. J. Glaciol., 58(212), 1119-1132 (doi: 10.3189/2012JoG12J018)

Adhikari S and Marshall SJ (2013) Influence of high-order mechanics on simulation of glacier response to climate change: insights from Haig Glacier, Canadian Rocky Mountains. Cryosphere, 7(5), 1527-1541 (doi: 10.5194/tc-7-1527-2013)

Aschwanden A and Blatter $\mathrm{H}$ (2005) Meltwater production due to strain heating in Storglaciären, Sweden. J. Geophys. Res., 110, F04024 (doi: 10.1029/2005JF000328)

Blatter H (1995) Velocity and stress fields in grounded glaciers: a simple algorithm for including deviatoric stress gradients. J. Glaciol., 41(138), 333-344

Bueler E and Brown J (2009) Shallow shelf approximation as a 'sliding law' in a thermomechanically coupled ice sheet model. J. Geophys. Res, 114, 1-21 (doi: 10.1029/2008JF001179)

Cornford SL and 8 others (2013) Adaptive mesh, finite volume modeling of marine ice sheets. J. Comput. Phys., 232(1), 529-549 (doi: 10.1016/j.jcp.2012.08.037)

Cuffey K and W.S.B. Paterson WSB (2010) The physics of glaciers, 4th edn. Butterworth-Heinemann, Oxford

Flowers GE Roux N, Pimentel S and Schoof CG (2011) Present dynamics and future prognosis of a slowly surging glacier. Cryosphere, 5(1), 299-313 (doi: 10.5194/tc-5-299-2011)

Gagliardini O, Cohen D, Råaback P and Zwinger T (2007) Finiteelement modeling of subglacial cavities and related friction law. J. Geophys. Res., 112(F2), F02027 (doi: 10.1029/2006JF000576)

Gagliardini $O$ and 14 others (2013) Capabilities and performance of Elmer/lce, a new-generation ice sheet model. Geosci. Model Dev., 6(4), 1299-1318 (doi: 10.5194/gmd-6-1299-2013)

Goldberg DN (2011) A variationally derived, depth-integrated approximation to a higher-order glaciological flow model. J. Glaciol., 57(201), 157-170 (doi: 10.3189/ 002214311795306763) 
Greve R and Blatter H (2009) Dynamics of ice sheets and glaciers. Springer, Berlin

Hutter K (1983) Theoretical glaciology: material science of ice and the mechanics of glaciers and ice sheets. Springer, Berlin

Huybrechts P (1990) A 3-D model for Antarctic ice sheet: a sensitivity study on the glacial-interglacial contrast. Climate Dyn., 5, 79-92

Huybrechts P, Payne T and the EISMINT Intercomparison Group (1996) The EISMINT benchmarks for testing ice-sheet models. Ann. Glaciol., 23, 1-12

Immerzeel WW, Van Beek LPH and Bierkens MFP (2010) Climate change will affect the Asian water towers. Science, 328(5984), 1382-1385 (doi: 10.1126/science.1183188)

Intergovernmental Panel on Climate Change (IPCC) (2013) Climate change 2013: the physical science basis. Contribution of Working Group I to the Fifth Assessment Report of the Intergovernmental Panel on Climate Change. Cambridge University Press, Cambridge

Larour E, Morlighem M, Seroussi H, Schiermeier J and Rignot E (2012) Ice flow sensitivity to geothermal heat flux of Pine Island Glacier, Antarctica. J. Geophys. Res., 117(F4), F04023 (doi: 10.1029/2012JF002371)

Le Meur E, Gagliardini O, Zwinger T and Ruokolainen J (2004) Glacier flow modelling: a comparison of the Shallow Ice Approximation and the full-Stokes solution. C. R. Phys., 5(7), 709-722 (doi: 10.1016/j.crhy.2004.10.001)

Leng W, Ju L, Gunzburger M, Price S and Ringler T (2012) A parallel high-order accurate finite element nonlinear Stokes ice sheet model and benchmark experiments. J. Geophys. Res., 117(F1) (doi: 10.1029/2011JF001962)

Leng W, Ju L, Gunzburger M and Price S (2013) Manufactured solutions and the verification of three-dimensional Stokes icesheet models. Cryosphere, 7(1), 19-29 (doi: 10.5194/tc-719-2013)

Leng W, Ju L, Gunzburger M and Price S (2014a) A parallel computational model for three-dimensional, thermo-mechanical Stokes flow simulations of glaciers and ice sheets. Commun. Comput. Phys., 16, 1056-1080 (doi: 10.4208/cicp.310813. 010414a)

Leng W, Ju L, Xie Y, Cui T and Gunzburger M (2014b) Finite element three-dimensional Stokes ice sheet dynamics model with enhanced local mass conservation. J. Comput. Phys., 274, 299-311 (doi:10.1016/j.jcp.2014.06.014)

Morland LW (1984) Thermo-mechanical balances of ice sheet flow. Geophys. Astrophys. Fluid Dyn., 29, 237-266

Morland LW (1987) Dynamics of the West Antarctic ice sheet. D Reidel Publishing Co., 99-116

Nye JF (1965) The flow of a glacier in a channel of rectangular, elliptic or parabolic cross-section. J. Glaciol., 5(41), 661-690

Oerlemans J (1986) An attempt to simulate historic front variations of Nigardsbreen, Norway. Theor. Appl. Climatol., 37, 126-135

Oerlemans J (1997) A flowline model for Nigardsbreen, Norway: projection of future glacier length based on dynamic calibration with the historic record. Ann. Glaciol., 24, 382-389
Pattyn F (2002) Transient glacier response with a higher-order numerical ice-flow model. J. Glaciol., 48(162), 467-477 (doi: 10.3189/172756502781831278)

Pattyn F (2003) A new three-dimensional higher-order thermomechanical ice sheet model: basic sensitivity, ice stream development, and ice flow across subglacial lakes. J. Geophys. Res., 108(B8), 2382 (doi: 10.1029/2002JB002329)

Pattyn F (2008) Investigating the stability of subglacial lakes with a full Stokes ice-sheet model. J. Glaciol., 54(185), 353-361 (doi: 10.3189/002214308784886171)

Pattyn F, Nolan M, Rabus B and Takahashi S (2005) Localized basal motion of a polythermal Arctic glacier: McCall Glacier, Alaska, USA. Ann. Glaciol., 40, 1-5 (doi: 10.3189/ 172756405781813537)

Pattyn F and 20 others (2008) Benchmark experiments for higherorder and full-Stokes ice sheet models (ISMIP-HOM). Cryosphere, 2(2), 95-108 (doi: 10.5194/tcd-2-111-2008)

Pimentel S, Flowers GE and Schoof CG (2010) A hydrologically coupled higher-order flow-band model of ice dynamics with a Coulomb friction sliding law. J. Geophys. Res., 115(F4), F04023 (doi: 10.1029/2009JF001621)

Price SF and Walder JS (2007) Modeling the dynamic response of a crater glacier to lava-dome emplacement: Mount St Helens, Washington, USA. Ann. Glaciol., 45, 21-28 (doi: 10.3189/ 172756407782282525)

Price SF, Waddington ED and Conway H (2007) A full-stress, thermomechanical flow band model using the finite volume method. J. Geophys. Res., 112(F3), F03020 (doi: 10.1029/ 2006JF000724)

Saito F, Abe-Ouchi A and Blatter H (2003) Effects of first-order stress gradients in an ice sheet evaluated by a three-dimensional thermomechanical model. Ann. Glaciol., 37, 166-172

Schoof C and Hewitt I (2012) Ice-sheet dynamics. Annu. Rev. Fluid Mech., 217-239 (doi: 10.1146/annurev-fluid-011212-140632)

Schoof C and Hindmarsh RCA (2010) Thin-film flows with wall slip: an asymptotic analysis of higher order glacier flow models. Q. J. Mech. Appl. Math., 63(1), 73-114 (doi: 10.1093/qjmam/ hbp025)

Seddik H, Greve R, Zwinger T, Gillet-Chaulet F and Gagliardini O (2012) Simulations of the Greenland ice sheet 100 years into the future with the full Stokes model Elmer/lce. J. Glaciol., 58(209), 427-440 (doi: 10.3189/2012JoG11J177)

Zhang T, Xiao C, Qin X, Hou D and Ding M (2012) Ice thickness observation and landform study of East Rongbuk Glacier, Mt Qomolangma. J. Glaciol. Geocryol., 34(5), 1059-1066 [in Chinese with English abstract]

Zhang $T$ and 7 others (2013) Observed and modelled ice temperature and velocity along the main flowline of East Rongbuk Glacier, Qomolangma (Mount Everest), Himalaya. J. Glaciol., 59, 438-448 (doi: 10.3189/2013JoG12J202)

Zwinger T, Greve R, Gagliardini O and Shiraiwa T (2007) A full Stokes-flow thermo-mechanical model for firn and ice applied to the Gorshkov crater glacier, Kamchatka. Ann. Glaciol., 45, $29-37$ 